\title{
Modeling of Laterally Sliding Motion of a Magnetic Clamp
}

\author{
A. Mahmud, J. R. R. Mayer, and L. Baron \\ Département de Génie Mécanique, École Polytechnique, 2900 Boulevard Édouard-Montpetit, Montréal, QC, Canada H3T 1J4
}

Correspondence should be addressed to A. Mahmud; apple.mahmud@polymtl.ca

Received 5 October 2015; Revised 26 November 2015; Accepted 29 November 2015

Academic Editor: Kim M. Liew

Copyright (C) 2015 A. Mahmud et al. This is an open access article distributed under the Creative Commons Attribution License, which permits unrestricted use, distribution, and reproduction in any medium, provided the original work is properly cited.

\begin{abstract}
A sliding magnetic clamp is used to hold a thin aluminum panel during a milling operation. The design includes a permanent magnet group follower (slave module) which slides laterally over the panel attracted by another permanent magnet group (master module) attached to the industrial robot end effector from the machined side of the panel. The lateral sliding motion of the slave module in response to the master module motion is studied using a transfer function based motion model established considering the lateral magnetic stiffness. The model is validated experimentally.
\end{abstract}

\section{Introduction}

This paper proposes a model for the lateral sliding motion of the master-to-slave module by magnetic attraction forces. The grasping end effector is intended to mill pockets in thin aircraft fuselage skin panels [1] with the support of magnetic clamping. The system is developed for holding a panel during milling operation. The clamping system includes two magnetic modules which are placed on either side of the panel. Figure 1 shows a general schematic of the grasping machining end effector [2].

The master module has three cylindrical permanent magnet sets, each set comprising three magnets (Figure 2). The milling cutter is at the center of the triangle formed by these three magnet sets. The slave module has a similar magnet arrangement. The master and slave work together as a clamp.

Elles and Lemarquand [3] describe radial stability characteristics in magnetic couplings used to transmit a torque through an air gap separation wall without any mechanical contact between the two rotors. The paper proposes two cylindrical-airgap magnetic couplings structures that transmit a torque but no radial displacement or vibration from the inner rotor to the outer rotor.

A cylindrical permanent magnet can generate both axial and radial forces. Lateral sliding is the result of radial forces.
Yonnet [4] defined lateral magnetic stiffness while discussing different magnetic properties for permanent magnetic bearings and couplings.

The slave module laterally follows the master module motion during machining operation. This slave motion caused by the master-slave magnetic attraction force has not yet been modeled. Vokoun et al. [5] calculated the attraction force between two cylindrical permanent magnets with a common axis considering the impact of lateral displacement on the axial attraction force. Later Mahmud et al. [6] modeled the lateral attraction force between cylindrical permanent magnets at different axial gap considering lateral displacement. A model is needed to describe the slave motion resulting from lateral magnetic attraction force between master and slave module. Without a model it is not possible to predict whether the slave would accurately follow the master or experience sluggish or stick-slip motion.

This paper develops the transfer function between the master module motion and slave module motion. First a simplified model is prepared for the mechanical and magnetic components. Then classical motion equations are used to describe the slave motion where lateral magnetic stiffness has been incorporated. Experiments are then conducted to validate the transfer function model. Finally conclusions are drawn. 


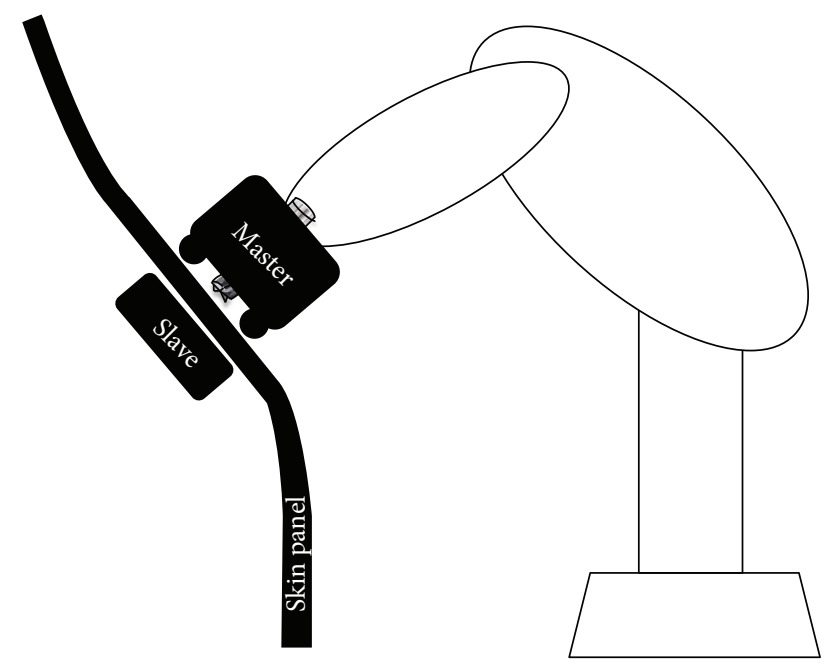

FIGURE 1: General schematic diagram of the grasping machining end effector concept.

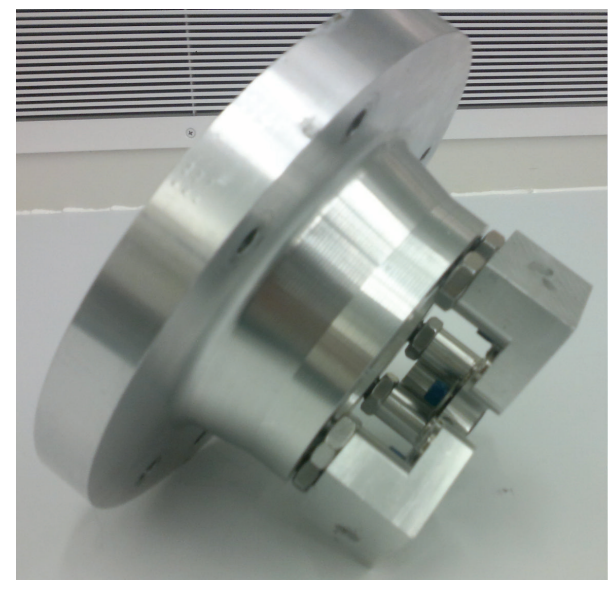

(a)

FIGURE 2: Master with three extended legs (a). Slave with three sets of permanent magnets (b) [7].

\section{Transfer Function Modeling}

A simplified $2 \mathrm{D}$ schematic of the system is presented in Figure 3. On top, the master module is fixed to the milling spindle outer body. The spindle is moved by a robot or a CNC machine tool. Each magnet of the slave module is subjected to a magnetic pull force $F_{z}$, out-of-plane, in the axial direction and a lateral force $F_{r}$, in-plane, in the radial direction [8]. Both the master and slave modules are subjected to frictional forces $F_{f m}$ and $F_{f s}$, respectively.

This model is a two-degree-of-freedom (in-plane and out-of-plane) mechanical system. The master module is the driver of the system. The slave module follows the master module due to the radial magnetic attraction force $F_{r}$.

The machine tool or robotic arm moves the master and causes a lateral displacement $r_{1}$. An $r_{2}$ displacement response is imparted to the slave $m_{2}$ by the radial magnetic force

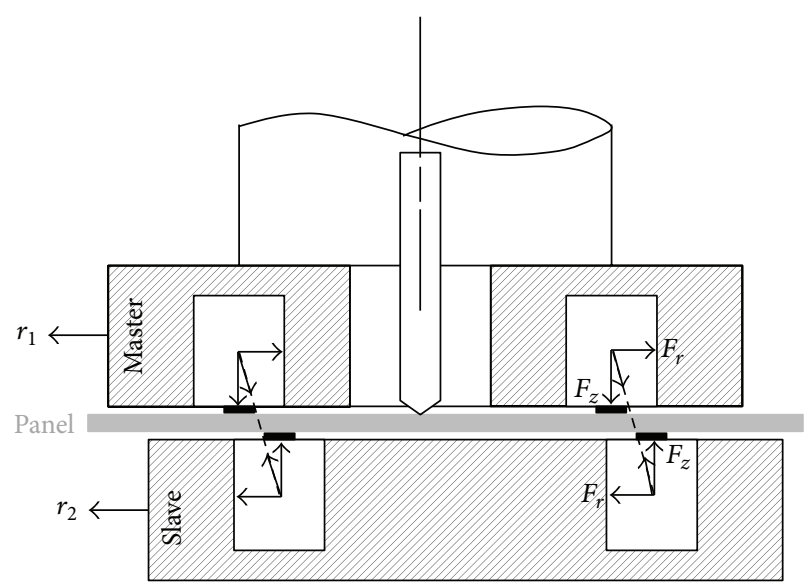

FIgURE 3: Master-slave magnetic forces in a simplified 2D view.
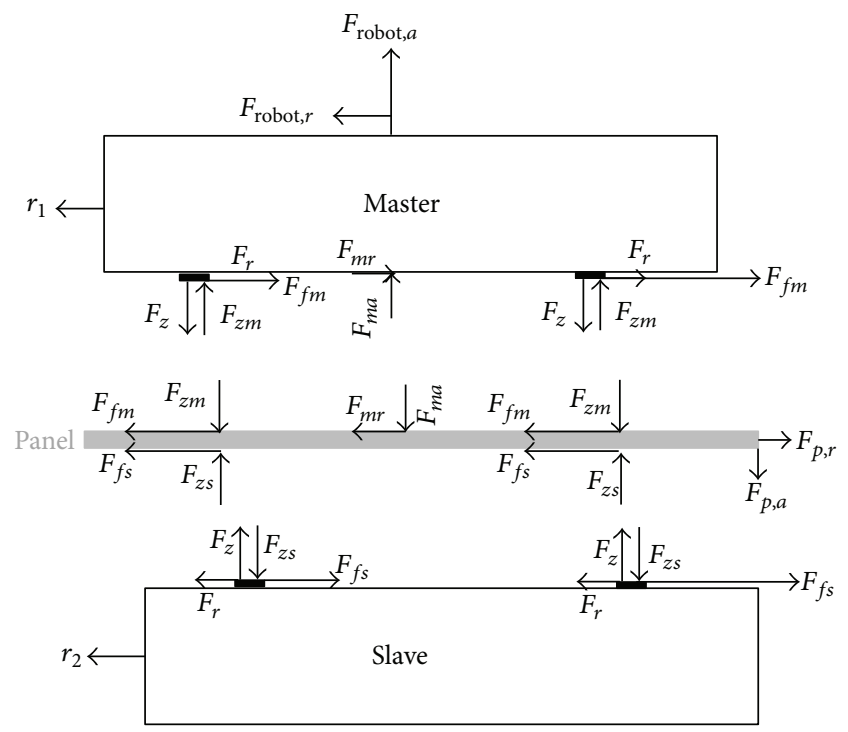

FIGURE 4: Free body diagram for panel-master-slave.

$F_{r},\left(F_{r}=K_{r}\left(r_{1}-r_{2}\right)\right)$ where $K_{r}$ is the lateral magnetic stiffness as defined by Yonnet [4].

A free body diagram for each of the system components (master, panel, and slave) is shown in Figure 4. The master is held by the robot by axial force $F_{\text {robot, } a}$. Master motion is dependent on the applied lateral force $F_{\text {robot }, r}$. In this analysis the robot is assumed to be sufficiently strong and stiff to generate the necessary force $F_{\text {robot, } r}$ to generate the desired input displacement $r_{1}$. For the slave module the axial contact force is $F_{z s}$ and for the master it is $F_{z m}$ which is equal to the applied axial magnetic force $F_{z}$. The cutter applies a milling thrust force $F_{m a}$ and radial force $F_{m r}$ to the thin skin panel.

First let us consider a simplified model without friction. If the master and slave are just pulled apart by holding the slave by a string arrangement (Figures 7 and 8 ) without placing any plate between them there is no friction. All vertical force components can be ignored just for the time being since they do not have any contribution to lateral motion. Milling forces are ignored in the absence of milling operation. 


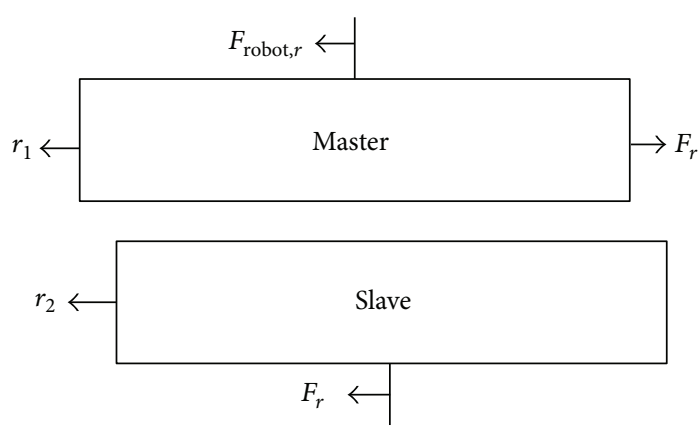

FIGURE 5: Modified free body diagram for master and slave.

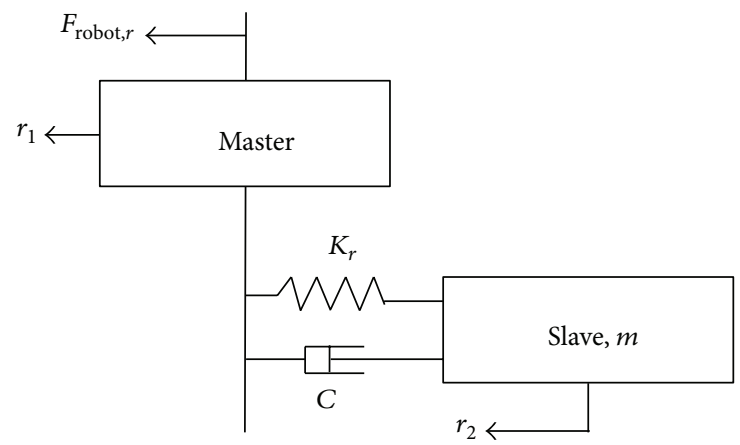

FIGURE 6: Master-slave equivalent mechanical system without the panel and associated friction and milling force.

After elimination of all friction forces $\left(F_{f_{s}}\right.$ and $\left.F_{f m}\right)$ and vertical forces $\left(F_{z}, F_{z m}\right.$, and $\left.F_{z s}\right)$, only the radial magnetic force $F_{r}$ remains. The free body diagram is also simplified as in Figure 5.

Assuming the slave has a mass $m$ and damping coefficient $C$ (air viscosity, string attachments) and the magnetic lateral stiffness $K_{r}$ an equivalent single degree of freedom massspring-damper mechanical system is used to model the system as shown in Figure 6.

A single degree of freedom damped spring mass system with a moving support or base (base excitation) has been described by Hundal [9]. Here the master motion $r_{1}(t)$ is the system input so the differential equation of motion without friction is

$$
m \ddot{r_{2}}+C \dot{r_{2}}+K_{r} r_{2}=C \dot{r_{1}}+K_{r} r_{1}
$$

Applying Laplace transform to this equation gives (assuming zero initial conditions)

$$
\left(m s^{2}+C s+K_{r}\right) R_{2}(s)=\left(C s+K_{r}\right) R_{1}(s)
$$

and the system transfer function becomes

$$
\frac{R_{2}(s)}{R_{1}(s)}=\frac{C s+K_{r}}{m s^{2}+C s+K_{r}} .
$$

We now include friction to complete the transfer function modeling. This requires considering the skin panel between the master and slave.
Sliding friction or dry friction which is considered as coulomb friction is modeled as a viscously damped system with an equivalent viscous damping coefficient [10]:

$$
C_{\mathrm{eq}}=\frac{4 \mu_{k} F_{z}}{\pi \omega X}
$$

where $X$ is the approximate amplitude of the steady state motion assuming both the slave and panel surface are well lubricated ensuring a viscous medium. Consider

$$
X=\frac{F_{\text {robot }, r}}{K_{r}} \sqrt{\frac{1-\left(4 \mu_{k} F_{z} / \pi F_{\text {robot }, r}\right)^{2}}{\left|\left(1-\left(\omega / \omega_{n}\right)^{2}\right)\right|}} .
$$

Here $\omega$ is the frequency of motion, $\omega_{n}$ is the natural frequency of the slave, and $F_{\text {robot, } r}$ is the driving force applied on the master causing the motion.

Equations (4) and (5) are based on the applied force $F_{\text {robot }, r}$ applied on the master. Applied driving force input is equal to the master displacement multiplied by stiffness $\left(F_{\text {robot }, r}=r_{1} * K_{r}\right)$. So (5) can be rewritten considering master displacement $r_{1}$ as input instead of the applied force:

$$
X=\sqrt{\frac{r_{1}{ }^{2}-\left(4 \mu_{k} F_{z} / \pi K_{r}\right)^{2}}{\left|\left(1-\left(\omega / \omega_{n}\right)^{2}\right)\right|}} .
$$

The slave applies an axial magnetic force $F_{z}$ on the skin panel. For the slave the equivalent viscous damping coefficient is $C_{\text {eq }}$. The master-to-slave transfer function (3) is rewritten with equivalent viscous damping coefficient to consider the fiction interfering during the milling operation. Consider

$$
\frac{R_{2}(s)}{R_{1}(s)}=\frac{C_{\mathrm{eq}} s+K_{r}}{m s^{2}+C_{\mathrm{eq}} s+K_{r}} .
$$

\section{System Parameter Identification}

The slave mass $m$ viscous damping coefficient $C$ and lateral magnetic stiffness $K_{r}$ need to be identified. The slave mass $m$ is $0.67 \mathrm{~kg}$ as measured on a weighing scale.

Direct force measurement with a spring balance provides stiffness value and subsequent calculation yields the undamped natural frequency. Figure 7 shows the preliminary test setup where a gap of $5 \mathrm{~mm}$ is maintained by string arrangement between the master and slave which represent the thickness of a panel to machine. For a $0.003 \mathrm{~m}$ lateral (radial) displacement $43.51 \mathrm{~N}$ is needed yielding stiffness $(K=F / \delta)$ of $14500 \mathrm{~N} / \mathrm{m}$. The undamped natural frequency is calculated as

$$
\omega_{n}=\sqrt{\frac{K}{m}}=\sqrt{\frac{1.4504 E+04}{0.67}}=147.13 \mathrm{rad} / \mathrm{sec} .
$$

Using the same string arrangement setup (Figure 8) a series of impact hammer tests were conducted to identify the damping and lateral magnetic stiffness for different gap values. 


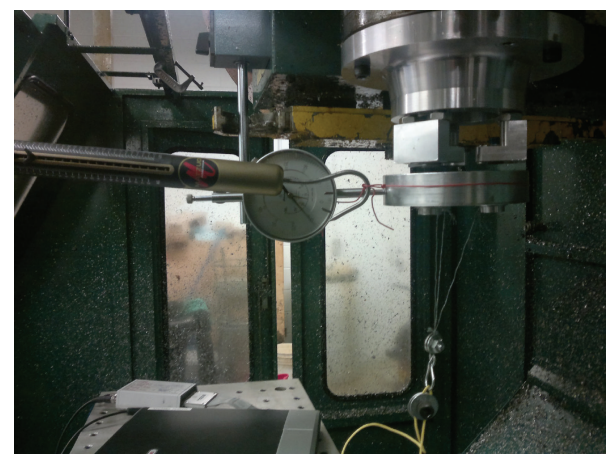

Figure 7: Lateral stiffness measurement by manual lateral force measurement with spring balance.

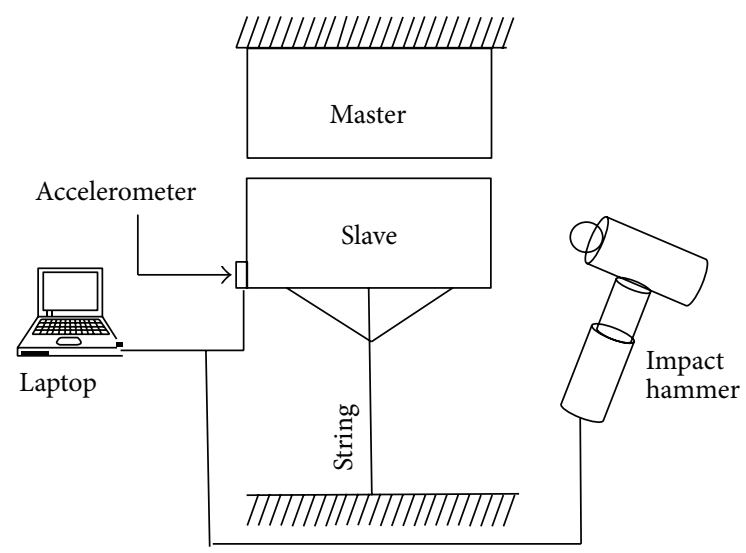

FIGURE 8: Test setup for system parameter identification.

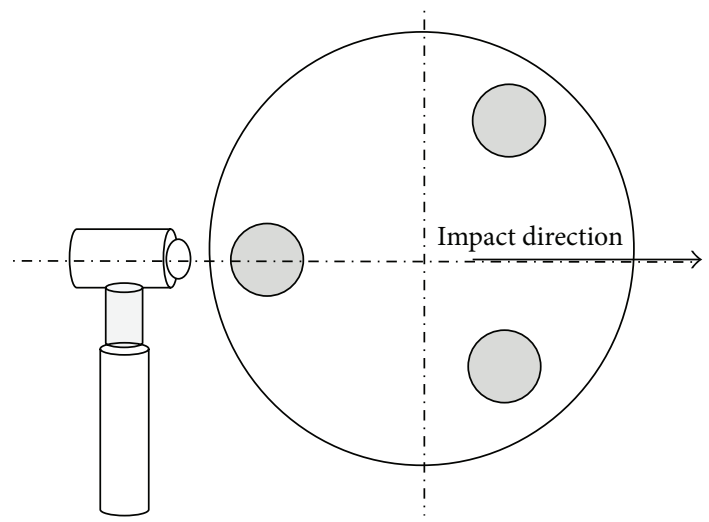

FIGURE 9: Impact force direction on the slave module during impact hammer test.

While making impact test on the slave module it was ensured that the hammer impact direction remained aligned with the center line as shown in Figure 9. This additional precaution ensures that the impact force did not create any rotational torque between the master and slave modules.

One miniature single axis accelerometer (model number $352 \mathrm{C} 22$, sensitivity $10 \mathrm{mV} / \mathrm{g}$ ) and an impact hammer (model number $086 \mathrm{D} 05$, sensitivity $0.23 \mathrm{mV} / \mathrm{N}$ ) both from $P C B$

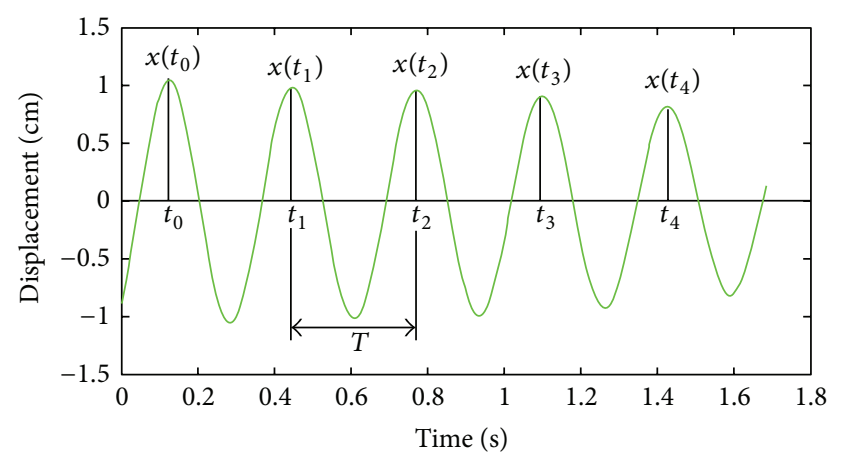

FIGURE 10: Displacement graph for a $5 \mathrm{~mm}$ gap between the master and slave.

PIEZOTRONICS were connected to MATLAB data acquisition program via NI data acquisition card DAQCard-A1-16E4. As soon as the hammer impacts the slave, vibrations are recorded. Acquired acceleration data were integrated twice to obtain the displacement data with respect to time. The calculated displacement profiles have been analyzed for slave damping and stiffness value.

Figure 10 shows the displacement pattern for a $5 \mathrm{~mm}$ gap between the master and slave. Immediately after the impulse force the slave continuously vibrates at its damped natural frequency.

Logarithmic decrement $\delta$ is applied for identifying the damping ratio [11]:

$$
\delta=\frac{1}{k} \log \left(\frac{x\left(t_{n}\right)}{x\left(t_{n+k}\right)}\right),
$$

where $x\left(t_{n}\right)$ is the displacement of the $n$th peak at the time $t_{n}$ and $k$ is the number of complete oscillations considered. Brincker et al. [12] convert the logarithmic decrement value to the damping ratio $\zeta$ :

$$
\zeta=\frac{\delta}{\sqrt{4 \pi^{2}+\delta^{2}}} .
$$

The damped natural frequency $\omega_{d}$ is calculated using $\delta$ and the oscillation period $T$ :

$$
\omega_{d}=\frac{\sqrt{4 \pi^{2}+\delta^{2}}}{T}, \quad \text { where } T=\frac{t_{n}-t_{0}}{n} .
$$

Then the required lateral magnetic stiffness coefficient $K_{r}$ value is calculated as follows:

$$
K_{r}=\omega_{n}^{2} m, \quad \text { where } \omega_{n}=\frac{\omega_{d}}{\sqrt{1-\zeta^{2}}} .
$$

Finally, the viscous damping coefficient is

$$
C=2 \sqrt{K_{r} m \zeta}
$$

A stiffness value of $14.967 \mathrm{E}+03 \mathrm{~N} / \mathrm{m}$ (Table 1) associated with a viscous damping value of $0.9090 \mathrm{~N}-\mathrm{sec} / \mathrm{m}$ has been calculated for the slave module for a gap of $5 \mathrm{~mm}$ between the 
TABLE 1: System identification experiments results summary.

\begin{tabular}{lcccc}
\hline Gap $(\mathrm{mm})$ & Natural freq. $\omega_{n}(\mathrm{rad} / \mathrm{sec})$ & Stiffness $K_{r}(\mathrm{~N} / \mathrm{m})$ & Damping ratio $\zeta$ & Damping coeff. $C(\mathrm{Ns} / \mathrm{m})$ \\
\hline 5 & 149.46 & 14967 & 0.0045 & 0.9090 \\
7 & 108.38 & 7870 & 0.0047 & 0.6869 \\
9 & 80.50 & 4342 & 0.0034 & 0.3627 \\
11 & 68.05 & 3103 & 0.0034 & 0.3096 \\
14 & 61.04 & 2497 & 0.0016 & 0.1307 \\
\hline
\end{tabular}

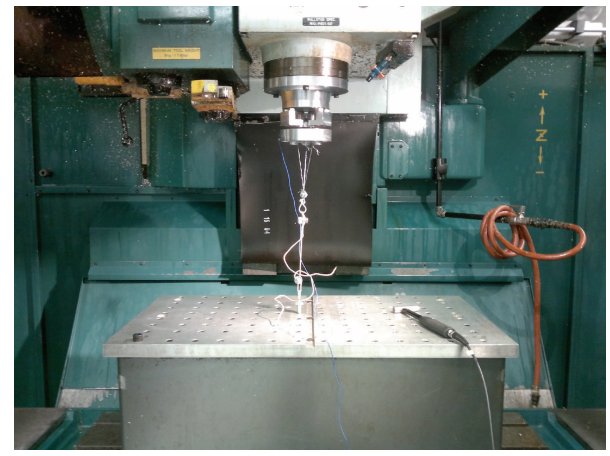

FIGURE 11: A $5 \mathrm{~mm}$ gap between the master and slave is maintained by a string arrangement.

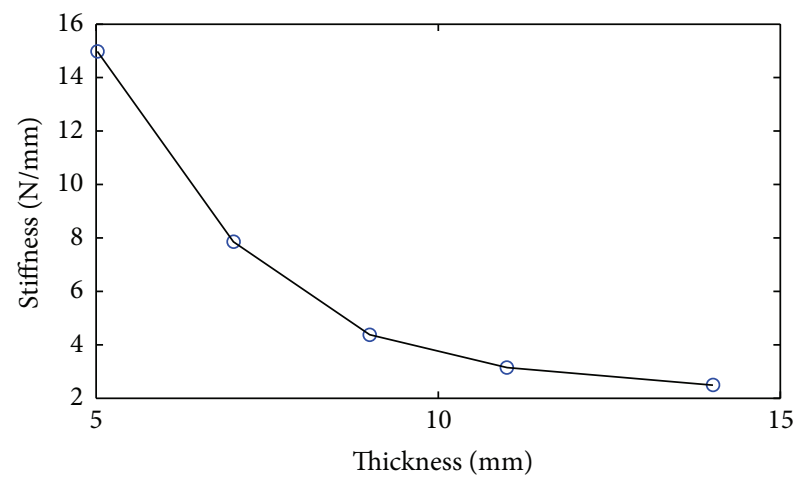

FIGURE 12: Stiffness reduces as the master-slave gap increases (thicker plate).

master and slave (Figure 11). This is in good agreement with the value of $K_{r}=14500 \mathrm{~N} / \mathrm{m}$ obtained from the static load test.

The measured mass and stiffness values yielded a calculated natural frequency of $147.13 \mathrm{rad} / \mathrm{sec}$ for a gap of $5 \mathrm{~mm}$ where the accelerometer based measurement and mathematical analysis results in a natural frequency of $149.46 \mathrm{rad} / \mathrm{sec}$.

The procedure was repeated for five gap values. Table 1 shows the results. The table also includes the natural frequency values and corresponding damping coefficients.

Damping coefficient generally decreased with an increased gap. In case of stiffness a decreasing pattern is prominent. Figure 12 shows that the stiffness value is decreasing as the gap increases.

During a real milling operation the master and slave will hold the aluminum panel and friction will occur during the

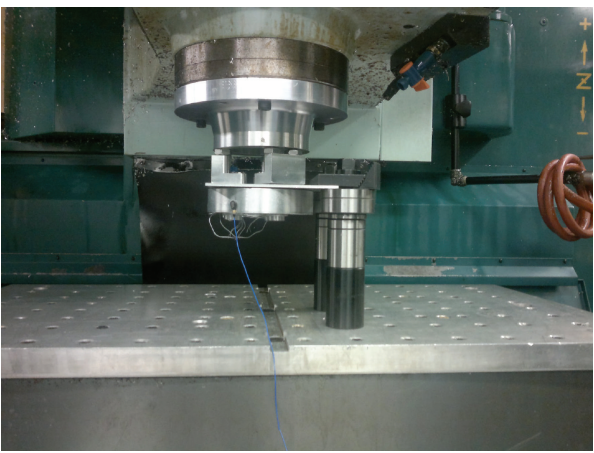

FIGURE 13: Plate between master and slave placed where accelerometer is positioned on the slave.

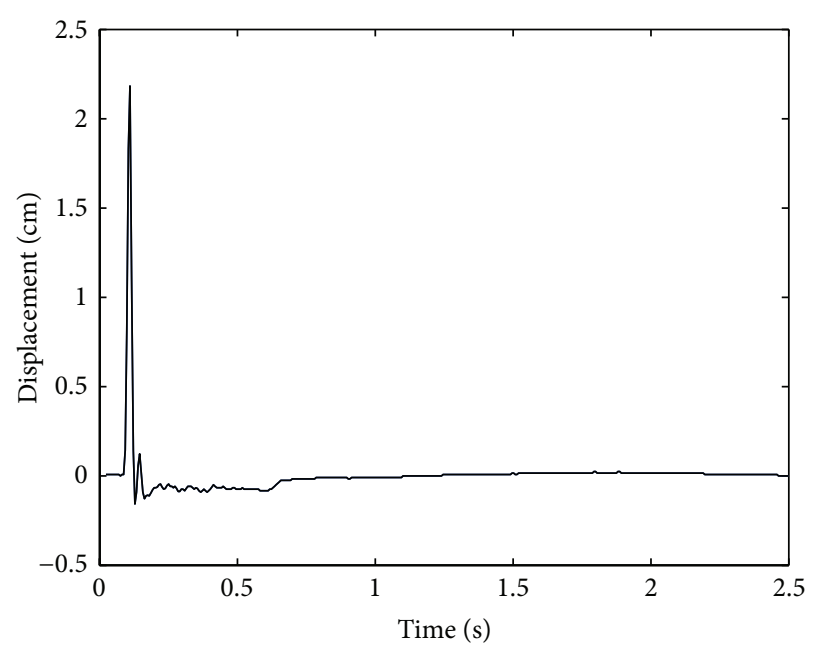

FIGURE 14: Slave displacement result for the impact hammer test of Figure 13.

sliding motion. So, an experimental setup has been realized to test the friction. The plate is clamped cantilevered. Both the manual (spring balance) and accelerometer based process are used for this setup to get the friction parameter.

A thin aluminum plate of thickness $2.54 \mathrm{~mm}$ with $1.25 \mathrm{~mm}$ slide pad on both sides makes a gap of $5.04 \mathrm{~mm}$. The impact hammer test procedure is completed. Since the captured accelerometer data did not show any regular sinusoidal vibration pattern as shown in Figure 14, logarithmic decrement based equation was not feasible for identifying the system parameter. 
TABLE 2: Friction force at different plate thickness.

\begin{tabular}{lcccc}
\hline Plate thickness $(\mathrm{mm})$ & Pad thickness $(\mathrm{mm})$ & Total gap $(\mathrm{mm})$ & Max. axial force, $F_{z}(\mathrm{~N})$ & Frictional force $\left(\mu_{k} * F_{z}\right)(\mathrm{N})$ \\
\hline 2.54 & 2.5 & 5.04 & 66.64 & 11.32 \\
5.05 & 2.5 & 7.55 & 50.96 & 8.66 \\
6.22 & 2.5 & 8.72 & 41.16 & 6.99 \\
6.70 & 2.5 & 9.20 & 38.24 & 6.50 \\
\hline
\end{tabular}

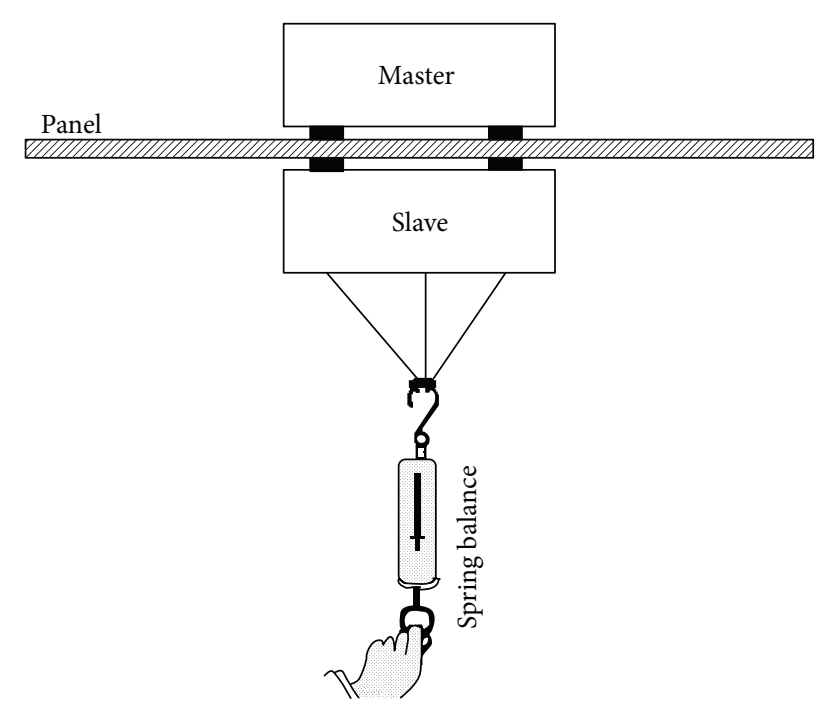

Figure 15: Test setup for axial force measurement by a spring balance.

Another test has been conducted with a spring balance to measure the lateral and axial magnetic force as shown in Figure 15. At this condition spring balance direct lateral force reading is $52.92 \mathrm{~N}$, and axial magnetic force, $F_{z}$, is $66.64 \mathrm{~N}$. Polyoxymethylene pad over aluminum panel has a friction coefficient $\mu_{k}$ of 0.17 [13]. The frictional force $\left(\mu_{k} * F_{z}\right)$ is $11.32 \mathrm{~N}$ which is used for the calculation of equivalent viscous damping coefficient. Table 2 lists the axial magnetic force between master and slave for plates of different thickness.

\section{Experiments and Results}

The derived transfer function model does not include milling force; only magnetic attraction forces are required. So, the transfer function validation experiment is designed without milling operation.

The master was moved by manual push and pull over a skin panel with the slave following the master. Both the master and slave experienced friction.

Two identical accelerometers are attached to the master module and the slave module (Figure 16). The first test is performed with a thin aluminum plate $(2.54 \mathrm{~mm}$, pad included total master-slave gap of $5.04 \mathrm{~mm}$ ).

Table 1 was obtained for tests without a plate between master and slave. Still, the same stiffness value would be accepted even if a plate is placed between master and salve because the stiffness is a function of distance between master and slave. This is because the stiffness is expected to come

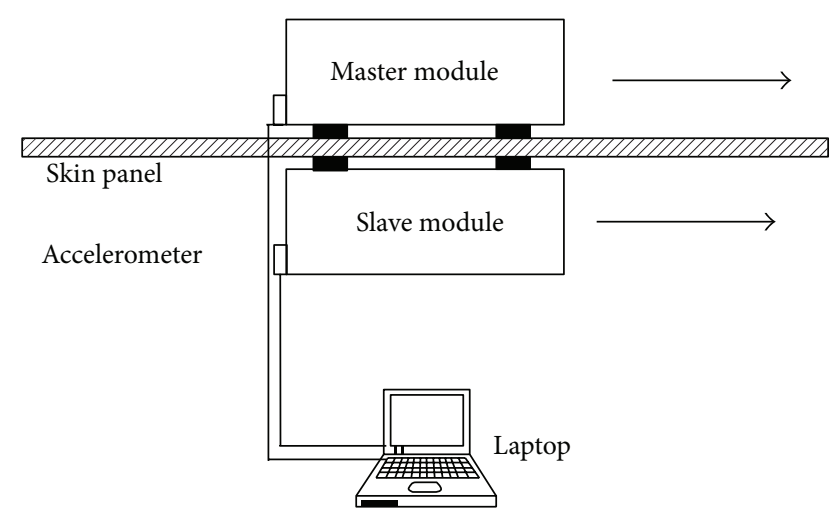

FIGURE 16: Simultaneous acceleration data acquisition for both master and slave.

from the magnetic force and a nonmagnetic plate does not influence the magnetic field. Inserting a plate would only change the damping because of friction. So an equivalent viscous damping coefficient has been calculated based on (4).

Data acquisition sampling frequency value is $10,000 \mathrm{~Hz}$. Frictional force value from Table 2 has been used for calculating steady state slave motion amplitude, $X$. Equivalent viscous damping coefficient has been calculated for each steady state slave displacement by (6). For a $2.54 \mathrm{~mm}$ thick skin panel the transfer function has been defined as follows based on the transfer function model (7). Consider

$$
\frac{R_{2}(s)}{R_{1}(s)}=\frac{C_{\mathrm{eq}} s+1.4966 E+04}{0.67 s^{2}+C_{\mathrm{eq}} s+1.4966 E+04} .
$$

Figure 17 is obtained after plotting the master and slave motion response from accelerometer reading. On the top master displacement is presented. On the bottom slave displacement is presented in a solid line. An additional dotted line is also plotted to show the simulated slave displacement based on the derived master-to-slave transfer function.

$R$-square value [14] is calculated for the simulated slave displacement with respect to the measured slave displacement for a gap of $5.04 \mathrm{~mm}$. An $R$-square value of 0.89 has been calculated showing the acceptability of the proposed slave motion model.

Magnetic stiffness was used as the prime constituent of the proposed master-slave motion transfer function. Since magnetic stiffness is highly dependent on the gap between the master and slave, one more experiment has been accomplished with a thicker skin panel of $5.05 \mathrm{~mm}$ (total gap $7.55 \mathrm{~mm}$ ) for a reduced stiffness value of $7.8700 \mathrm{E}+03 \mathrm{~N} / \mathrm{m}$. In this case the axial magnetic force is $50.96 \mathrm{~N}$. The transfer 

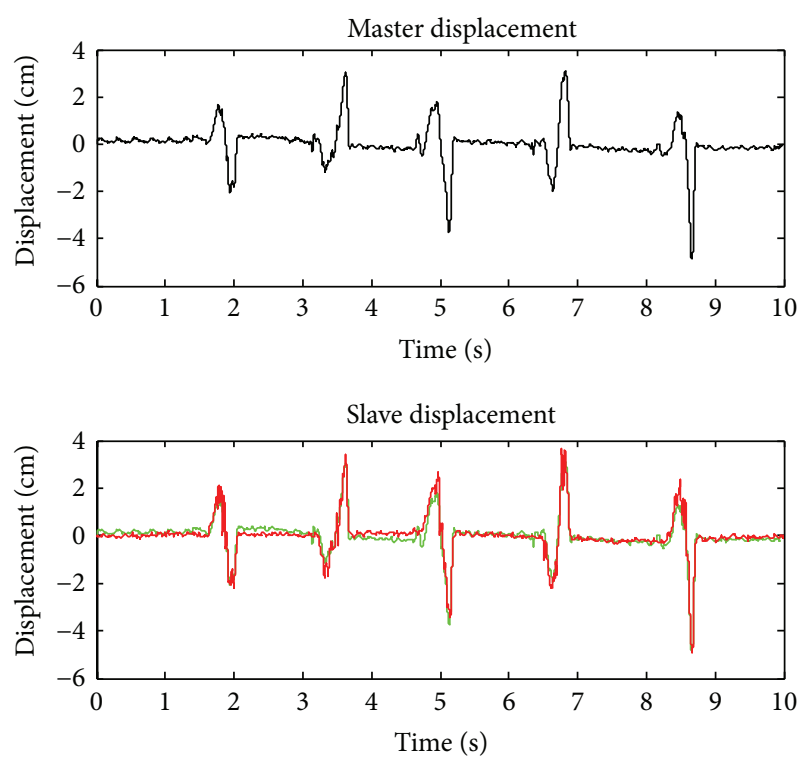

_ Simulated displacement

— Measured displacement

FIGURE 17: Comparison of transfer function based simulated motion to the actual slave motion (master-slave gap $5.04 \mathrm{~mm}$ ).
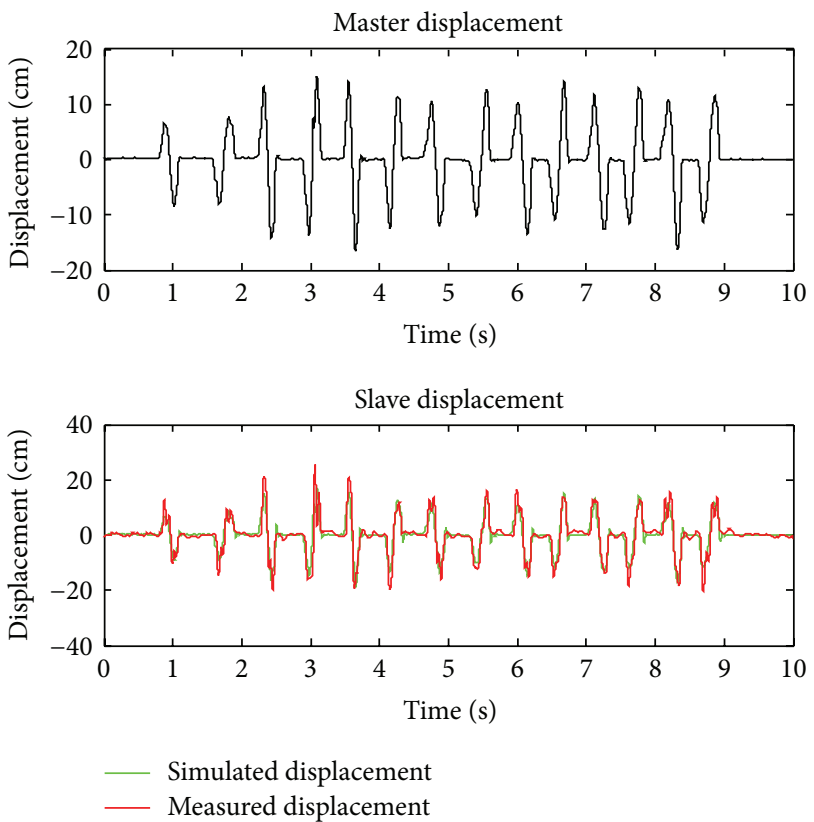

FIGURE 18: Comparison of transfer function based simulated motion to the actual slave motion (master-slave gap $7.55 \mathrm{~mm}$ ).

function $R_{2}(s) / R_{1}(s)$ is still valid to predict the slave motion to an acceptable level, associated with an $R$-square value of 0.8340 as shown in Figure 18.

\section{Conclusion}

During the skin panel milling operation the robot drive master module will follow the instructed tool path based on the required pocket dimension, but the slave motion is dependent on the magnetic attraction force against its inertia and the frictional force. A master-to-slave motion transfer function is proposed to calculate the slave response. The proposed transfer function based motion model was able to predict the slave position based on the input master motion. Though this paper only considers the lateral sliding motion in case of real pocket milling operation there will be rotational motion too. An in-depth rotational motion analysis would be relevant as future work to predict the complete slave module motion response.

Spring balance direct measurement provided the lateral stiffness values later verified by logarithmic decrement formula based calculation. But the most critical part of the system parameter identification is damping values. While sliding over the skin panel the slave confronts coulomb friction. Equivalent viscous damping coefficient has been used for the transfer function.

The master-to-slave transfer function is based on three parameters, slave mass, lateral magnetic stiffness, and damping coefficient. This specific project had a slave module of $0.67 \mathrm{~kg}$ with an approximate lateral stiffness of $14500 \mathrm{~N} / \mathrm{m}$. Two independent experiments with different thickness skin panel have been tested to verify the transfer function model acceptability. Both of the test results satisfactorily validated the model suitability.

\section{Conflict of Interests}

The authors declare that there is no conflict of interests regarding the publication of this paper.

\section{Acknowledgment}

This work was supported by the project of "Machining of Skin Panels (Al or Al-Li)," CRIAQ MANU-412-NSERC RDCPJ 411911-10.

\section{References}

[1] S. Castagne, R. Curran, and P. Collopy, "Implementation of value-driven optimisation for the design of aircraft fuselage panels," International Journal of Production Economics, vol. 117, no. 2, pp. 381-388, 2009.

[2] A. Mahmud, J. R. R. Mayer, and L. Baron, "Determining the minimum clamping force by cutting force simulation in aerospace fuselage pocket machining," The International Journal of Advanced Manufacturing Technology, vol. 80, no. 9-12, pp. 17511758, 2015.

[3] P. Elles and G. Lemarquand, "Analytical study of radial stability of permanent-magnet synchronous couplings," IEEE Transactions on Magnetics, vol. 35, no. 4, pp. 2133-2136, 1999.

[4] J. P. Yonnet, "Permanent magnet bearings and couplings," IEEE Transactions on Magnetics, vol. 17, no. 1, pp. 1169-1173, 1981.

[5] D. Vokoun, M. Beleggia, L. Heller, and P. Šittner, "Magnetostatic interactions and forces between cylindrical permanent magnets," Journal of Magnetism and Magnetic Materials, vol. 321, no. 22, pp. 3758-3763, 2009. 
[6] A. Mahmud, J. Mayer, and L. Baron, "Magnetic attraction forces between permanent magnet group arrays in a mobile magnetic clamp for pocket machining," CIRP Journal of Manufacturing Science and Technology, vol. 11, pp. 82-88, 2015.

[7] A. Chouinard, Remplacement de l'usinage Chimique des Tooles Aeronautiques Minces en Aluminium par de l'usinage Mecanique, École Polytechnique de Montréal, Montréal, Canada, 2011.

[8] A. K. Ghosh and S. S. Hecker, "Stretching limits in sheet metals: in-plane versus out-of-plane deformation," Metallurgical Transactions, vol. 5, no. 10, pp. 2161-2164, 1974.

[9] M. S. Hundal, "Response of a base excited system with Coulomb and viscous friction," Journal of Sound and Vibration, vol. 64, no. 3, pp. 371-378, 1979.

[10] D. J. Inman and R. C. Singh, Engineering Vibration, vol. 3, Prentice-Hall, Upper Saddle River, NJ, USA, 2001.

[11] C.-H. Lamarque, S. Pernot, and A. Cuer, "Damping identification in multi-degree-of-freedom systems via a waveletlogarithmic decrement-part 1: theory," Journal of Sound and Vibration, vol. 235, no. 3, pp. 361-374, 2000.

[12] R. Brincker, C. Ventura, and P. Andersen, "Damping estimation by frequency domain decomposition," in Proceedings of the 19th International Modal Analysis Conference (IMAC '01), Kissimmee, Fla, USA, February 2001.

[13] H. Unal and A. Mimaroglu, "Friction and wear behaviour of unfilled engineering thermoplastics," Materials \& Design, vol. 24, no. 3, pp. 183-187, 2003.

[14] A. C. Cameron and F. A. G. Windmeijer, "R-squared measures for count data regression models with applications to healthcare utilization," Journal of Business \& Economic Statistics, vol. 14, no. 2, pp. 209-220, 1996. 

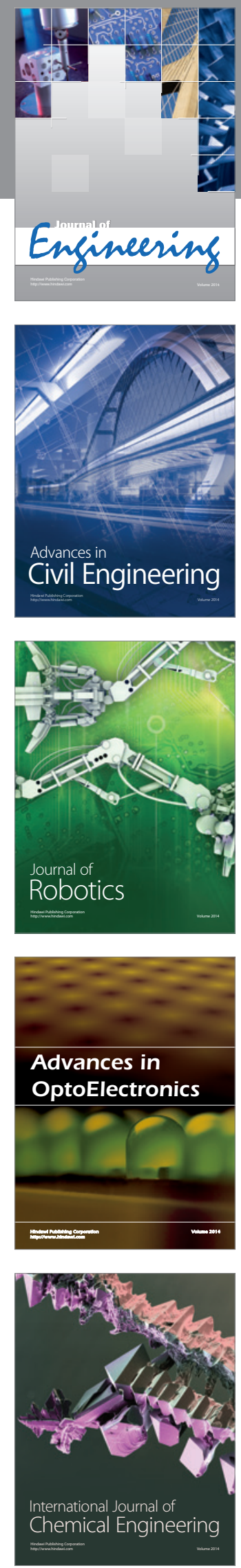

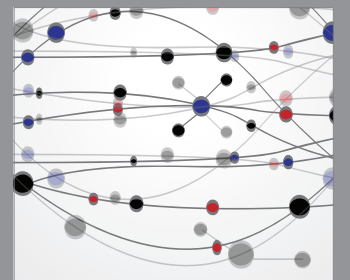

The Scientific World Journal
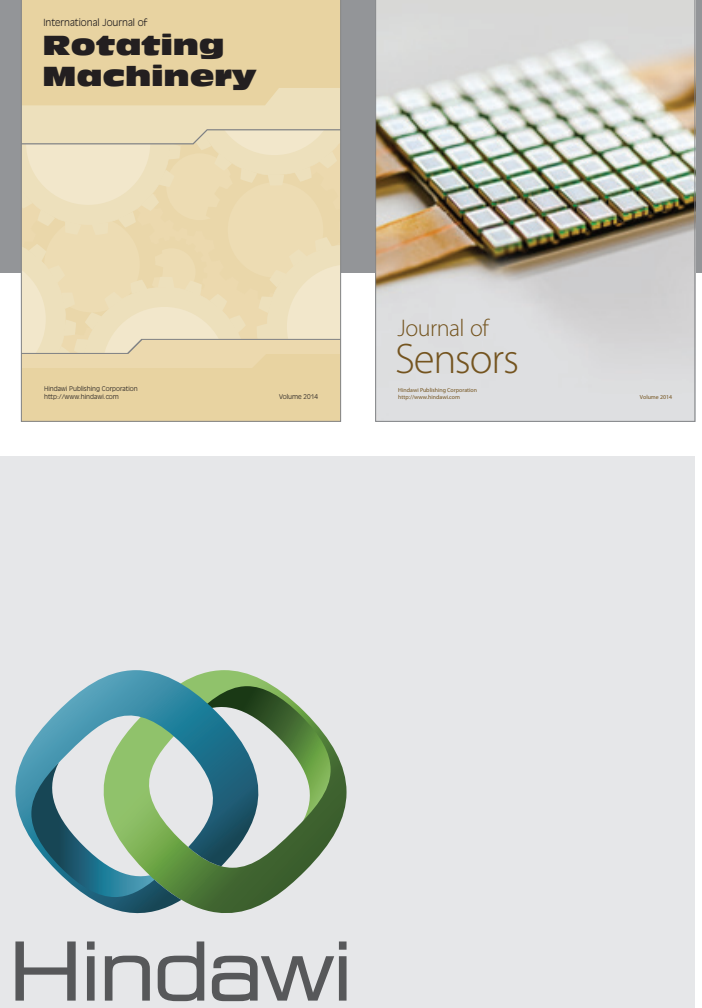

Submit your manuscripts at http://www.hindawi.com
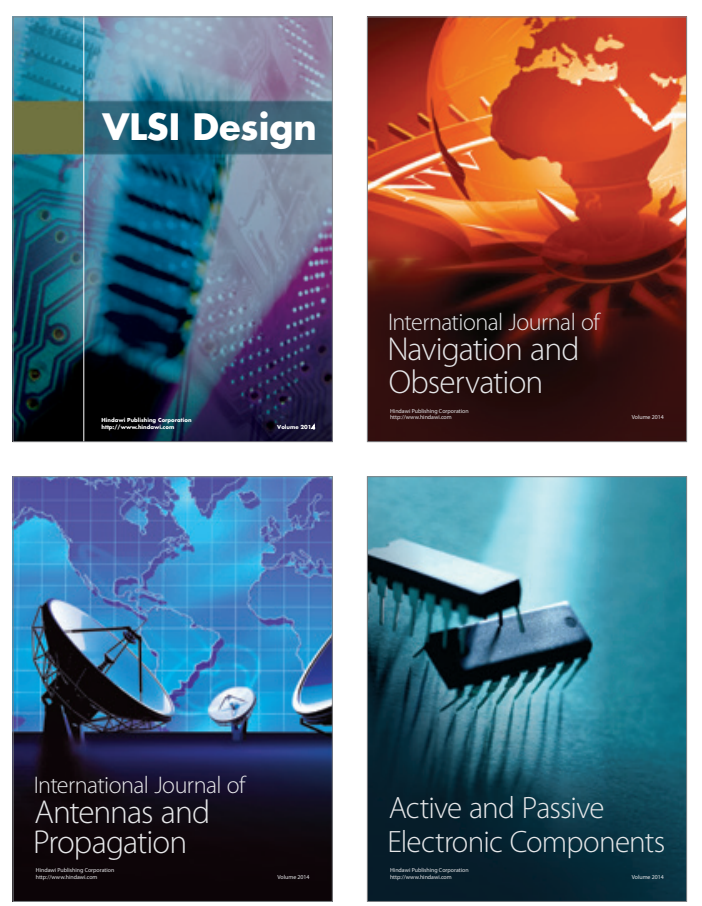
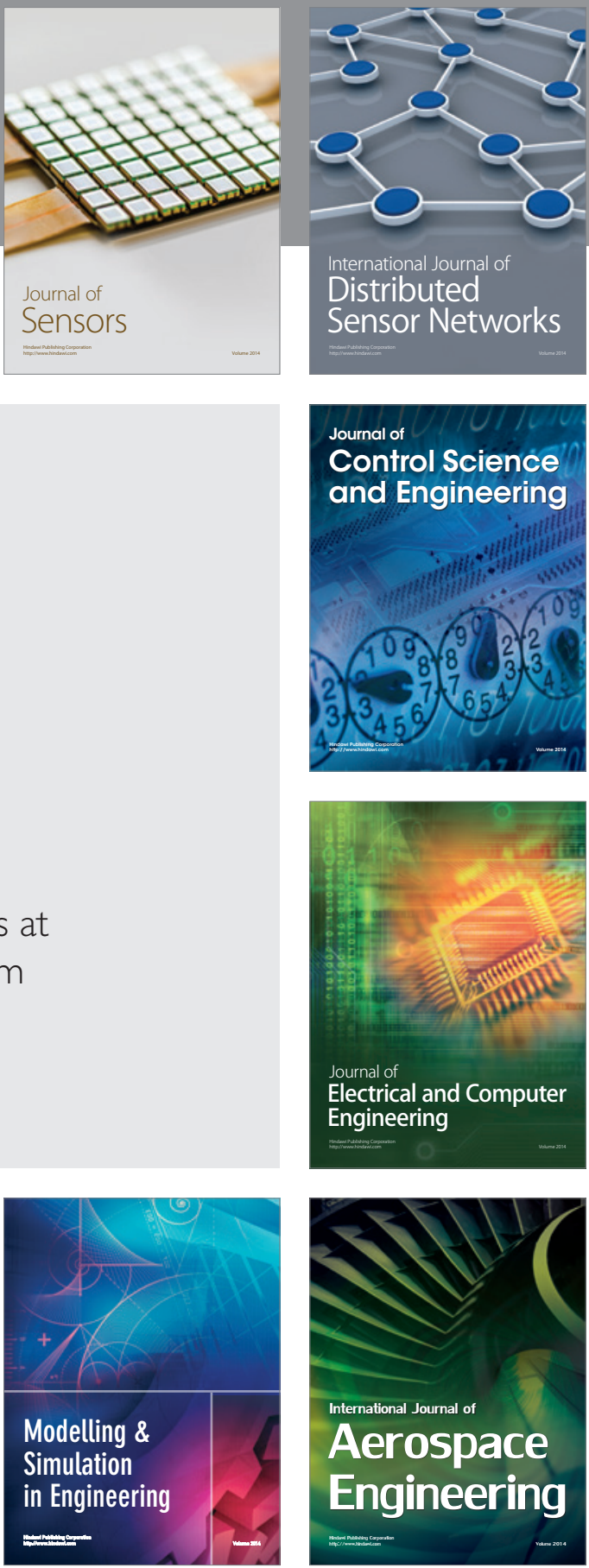

Journal of

Control Science

and Engineering
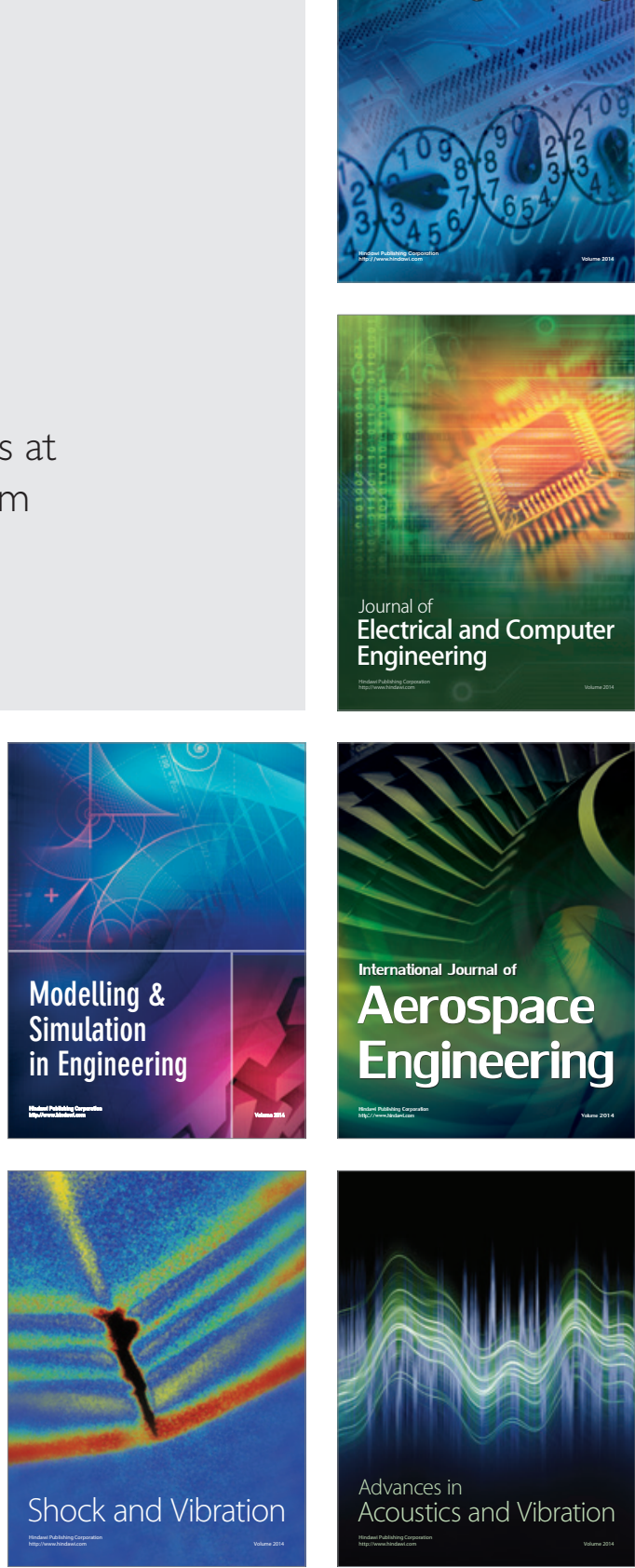